\section{Ein Pionier der frühen experimentellen Medizin: Marceli Nencki (1847-1901)}

M. H. Bickel

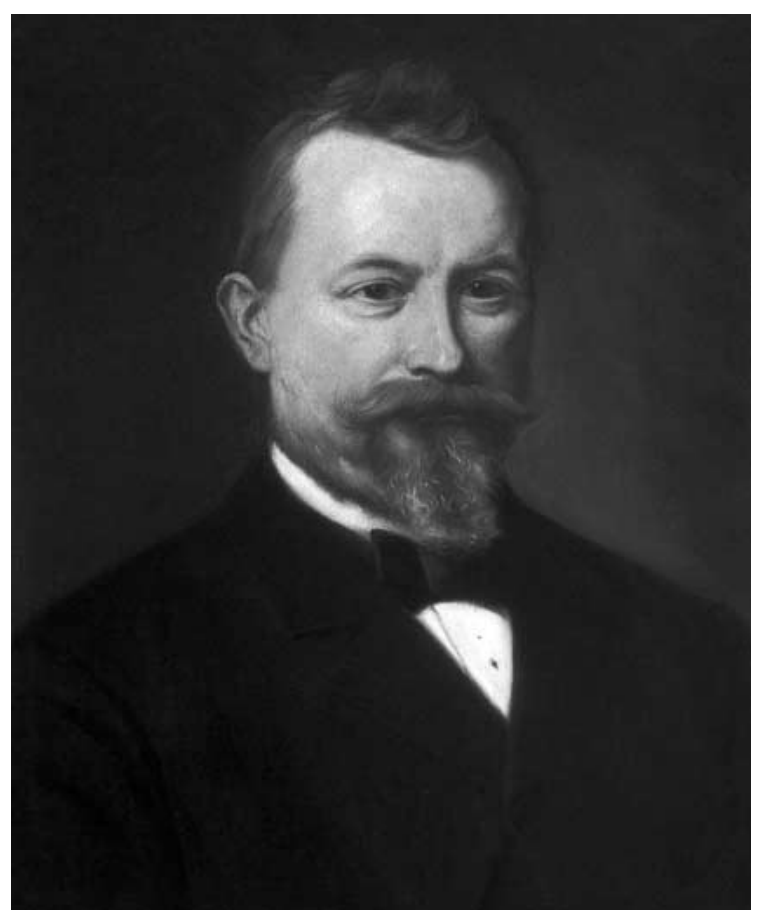

\begin{abstract}
Marceli Nencki. Porträt von Karl Gehri (1850-1922).
Im Besitz des Medizinhistorischen Instituts der Universität Bern.

dass er bereits 1876 zum Professor befördert und ihm gleichzeitig die Leitung des neu geschaffenen Medizinisch-Chemischen Instituts anvertraut wurde. So wurde das später Biochemie genannte Fach in Bern erstmalig in der Schweiz institutionalisiert. Nenckis Ruhm verbreitete sich durch die aus dem Institut hervorgehenden Arbeiten; Schüler strömten ihm aus Polen, Russland, Amerika zu. Auch seine Arbeitsumgebung wirkte stimulierend auf ihn. $\mathrm{Zu}$ seinen $\mathrm{Fa}-$ kultätskollegen gehörten die Anatomen T. Aeby und Strasser, die Physiologen Valentin und Kronecker, der Pathologe Langhans, ferner Theodor Kocher und die Internisten Quincke, Lichtheim und Sahli.

Nach 20 Jahren in Bern wechselte Nencki scheinbar überraschend nach St. Petersburg. Dahinter stand ein unwiderstehliches Angebot zur Leitung einer grossen Abteilung innerhalb des neuen Kaiserlichen Instituts für experimentelle Medizin, wo er auch mit Pawlow zusammenarbeiten konnte. Einem Kollegen schrieb er nach einem Jahr: «Mir geht es hier leidlich, das Land ist mir fremd, aber in meinem Laboratorium habe ich reichlich Mittel, um arbeiten zu können, und das ist für mich die Hauptsache." Nencki hat in St. Petersburg zwar viele seiner früheren Arbeiten zu einem Abschluss bringen und neue Gebiete eröffnen können, aber glücklich war er dort nicht. Seine Frau Maria, Schultzens Schwester, war nach Berlin zurückgekehrt und sein Sohn Leon zum Medizinstudium in Bern geblieben. Die sozialen und politischen Verhältnisse in Russland empfand Nencki, dieser nüchterne, allem Glanz und Getue abholde unabhängige Geist, als unerträglich. Er starb in St. Petersburg an einem Magenkarzinom im Alter von 54 Jahren. sche Chemie. Nencki kam nach Bern, betrübt, dass zin in Bern geworden war, einem Ruf nach Königsdass er auf sein neues Amt verzichten musste. Die Leistungen des jungen Nencki waren so überzeugend,

Vor hundert Jahren starb Marceli Nencki (sprich ten der Biochemie und auch der Bakteriologie beigetragen und sich für die Methodik der experimentelseine medizinische Ausbildung in Deutschland, seine wichtigsten 20 Schaffensjahre in der Schweiz und es um Nencki bald ruhig geworden. Nicht so in Polen, wo er als wissenschaftlicher Nationalheld gefeiert gen das Nencki-Institut für experimentelle Biologie protestantischen Friedhof sowie auch eine umfangpolnische Sekundärliteratur, die mit der sache kontrastiert, dass Nencki selbst die meiste Der 1847 im russisch annektierten Polen aufgewachsene Nencki absolvierte sein Medizinstudium in Angeregt durch seine älteren Studienfreunde Otto Schultzen und Bernhard Naunyn interessierte sich Baeyer. Dann erfolgte im Alter von 25 Jahren die Eintige Professor für Pathologie, war der Überzeugung, dass allen Lebensprozessen chemische Ereignisse zugrunde liegen und übertrug Nencki 1872 die Leitung Naunyn, der inzwischen Professor für innere Med
\end{abstract}

\footnotetext{
Prof. Dr. Marcel H. Bickel

Medizinhistorisches Institut

Bühlstrasse 26

CH-3012 Bern

Korrespondenz:

CH-3012 Bern
} 
Das Spektrum von Nenckis Arbeitsgebieten reichte von der organischen Chemie über Biochemie und Bakteriologie bis zu Infektionskrankheiten, Serumtherapie und Seuchenbekämpfung. Im Zentrum stand die Biochemie mit Themen wie Harnstoffbildung, Stoffwechsel körperfremder Verbindungen, Hämoglobin, Verdauung, Fäulnis und Enzyme.

\section{Literatur}

1 Sieber N, Zaleski J (eds.). Marceli Nencki, Opera Omnia. 2 Bde., Braunschweig; 1904

2 Bickel MH. Marceli Nencki, 1847-1901. Bern: Hans Huber; 1972. 